\title{
Perception and Practices Towards Pesticides and Associated Health Impacts Among Vegetable Farmers in Badulla
}

\author{
M. A. Sachintha Prasad Jayasinghe ${ }^{1}$ and Krishnal Thirumarpan ${ }^{1^{*}}$ \\ Date Received: $29^{\text {th }}$ July 2019 / Date Accepted: $8^{\text {th }}$ January 2020
}

\begin{abstract}
Purpose : Pesticides continued to be a significant component in vegetable production in Sri Lanka. But human health impacts due to pesticide exposure are not well documented even though acute poisoning is a major public problem today. Within this context, current study was conducted to assess the awareness of hazardous pesticides, usage and associated health impacts among vegetable farmers in Badulla district.

Research Method: Information pertaining to the study was collected from primary sources and secondary sources. Hundred vegetable farmers from Badulla district were interviewed using structured pre tested questionnaires. Descriptive statistic, frequency distribution and t test were employed to examine the relationships.

Findings : Almost all the farmers depended on the chemical pesticides. 94\% of farmers used Zoro (Abamactin) and $85 \%$ offarmers used Calcrone (Profenofos), which are extremely hazardous insecticides. Almost all farmers identified the pictogram of "wearing gloves". About $75 \%$ of respondents were affected by any type of acute disease due to pesticide application. $52 \%$ were affected by skin problems like itching. Among them $98.67 \%$ took treatments. A significant difference was observed between those who participated in training and others on acute diseases $(P<0.05)$, and those used masks and non-users on acute diseases $(P<0.05)$.
\end{abstract}

Research Limitations : Hospital data related to illness or poisoning due to pesticides was lacking in the study area.

Originality/Value : It is evident from the study that farmers are mishandling and overusing pesticides which leads to diseases and the need for pesticides related education to farmers.

Keywords: Pesticides, hazardous level, acute diseases, health impacts, vegetable farmers

\section{INTRODUCTION}

Sri Lanka is an agricultural country as the majority of the rural people is still engaged in agriculture for their main livelihood. Agriculture is an important sector in the economy contributing to $6.8 \%$ as a share of the Gross Domestic Product for the year 2017 (Central Bank Report, 2018). According to Marasinghe (2009), certain provinces had the highest contribution to Agriculture and they are Uva, North Central and Central provinces.

Pesticides have found to be a major part in present day farming, and play a major role in increasing agricultural productivity (Jallowet $a$ l., 2017). Pesticides are not only used to control insect pets, weeds and pathogens but also used to control vector borne diseases (Bolognesi and
Merlo, 2011). There are many kinds of benefits that may be attributed to pesticides and the most obvious benefits to calculate are economic benefits for the farmers derived from preventing or reducing agricultural losses, quality and the reduction of other costly inputs such as labor and fuel. However, despite their benefits, pesticides pose potential hazards to human health and the environment when inappropriately handled (Kishi, 2005). Misuse and overuse of pesticides lead to both direct and indirect environmental

$I^{*}$ Department of Agricultural Economics, Faculty of Agriculture Eastern University, Sri Lanka

skrish_16@yahoo.com

DD ORCID http://orcid.org/0000-0003-4735-4888 
effects. The indirect effects include negative impacts on human health, degradation of the environment, loss of biodiversity and irreversible changes to ecosystems.

Human health impacts due to pesticide exposure are also not well documented in the country. In several agricultural districts in the island, it precedes all other causes of death in government hospitals (Van der hoek etal., 1998). Wilson and Tiddsell (2001) in their study argued that farmers from Sri Lanka mostly ignore technical recommendations and apply pesticides on their own experience often leading to indiscriminate usage. Yet, some farmers have problems related to inadequate knowledge and information on usage of pesticides and finally get affected with different illnesses. Most of the acute poisoning cases are intentional (suicide) and occur among young adults, mainly males and poisoning due to occupational exposure is also common, but less well documented (Van der hoek et al., 1998).

Badulla district is in the Uva Province of Sri Lanka and mainly the economy of the district is based on agricultural farming and livestock where tea, vegetable and paddy are cultivated. Mainly the district is divided into two portions as Upper region and Lower region according to climatic and geographical characteristics. Upper division of the district is famous for tea plantation and vegetable cultivation while lower division is famous for paddy cultivation. Here, vegetable farmers were heavily dependent on agrochemicals. However, studies related to the awareness of hazardous pesticides and knowledge on associated health impact on farmers are very rare in Badulla district. Therefore, the present study was conducted to assess the perception, awareness on pesticide usage and associated effect on vegetable farmers' health in Badulla district. The specific objectives were to determine the socio-economic status of vegetable farmers, to analyze the farmers' awareness on safety usage of pesticide, to analyze the health cost for diseases caused by pesticide exposure and to analyze the associated health impact of pesticide usage.

\section{RESEARCH METHODOLOGY}

\section{Study Area}

This study was conducted in three Divisional Secretariat Divisions in the upper division of Badulla District. Badulla district is in the Uva Province of Sri Lanka and the district is divided into two portions as Upper region and Lower region according to climatic and geographical characteristics. Upper division of the district is famous for tea plantation and vegetable cultivation while lower division is famous for paddy cultivation (Figure 01).

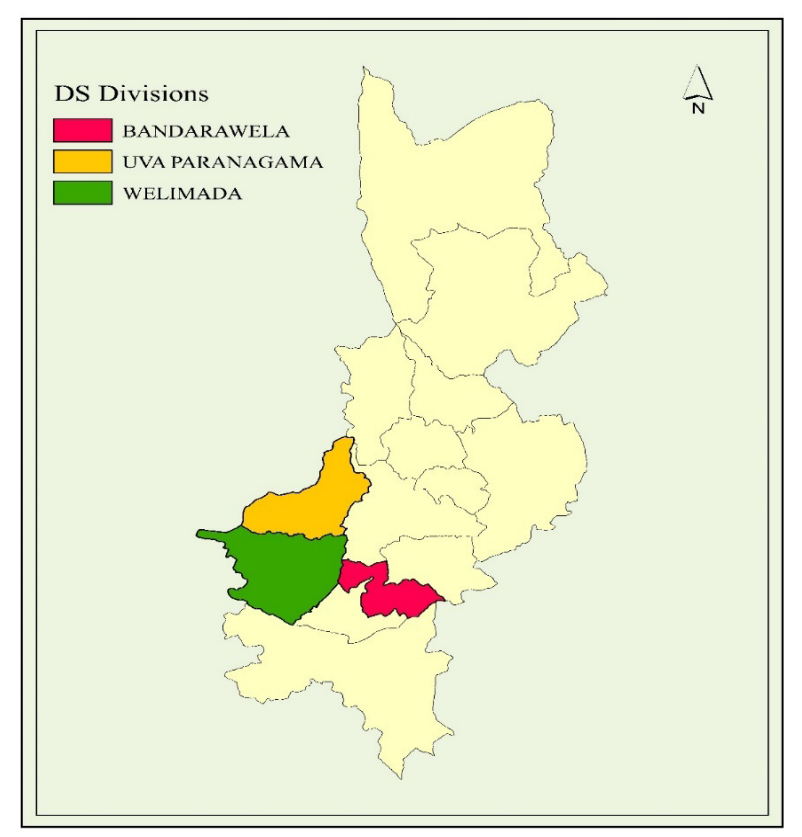

Figure 01: Location of the study area 


\section{Data collection}

The Grama Niladhari Divisions were selected on the basis of the degree of total number of vegetable cultivating families from selected areas. Proportionate sampling was done from Uva-Paranagama, Welimada and Bandarawela Divisional Secretariat (DS) Divisions and thirty-five, thirty-one and thirty-four samples were collected respectively from each DS Division. Thus, the final sample consisted of 100 respondents. They were interviewed at their farming site. Before the commencement of the data collection, the questionnaires were pre tested to assess the suitability of the Questionnaires. Modifications were done to enable easy recording of responses from vegetable cultivating farmers. Secondary data were collected from Divisional Secretariats of the selected DS division and Department of Agriculture.

\section{Data Analysis}

Descriptive statistics were done for questionnaires to explore the socioeconomic status of vegetable farmers, to assess the different types of pesticides used and to analyze health impact of pesticide usage. An independentsamples t-test was conducted to compare occurrence of Acute disease in respondents with selected independent variables.

\section{Hypothesis test for the t-test between participation in training program and Acute disease}

\section{Null Hypothesis $\left(H_{\theta}\right)$ :}

There is no significant difference between mean of respondents who participated in the training program and who did not participate in the training program on occurrence of Acute disease.

\section{Alternative Hypothesis $\left(H_{1}\right)$ :}

There is a significant difference between mean of respondents who participated in the training program and who did not participate in the training program on occurrence of Acute disease.

\section{Hypothesis for the t-test between usage of mask and Acute disease}

Null Hypothesis $\left(H_{\theta}\right)$ :

There is no significance difference between mean of mask users and non-mask users on occurrence of Acute disease.

Alternative Hypothesis $\left(H_{P}\right)$ :

There is a significant difference between mean of mask users and respondents who don't use mask on occurrence of Acute disease.

\section{Hypothesis test for the t-test between usage of gloves and Acute disease}

Null Hypothesis $\left(H_{\theta}\right)$ :

There is no significant difference between mean of gloves users and respondents who do not use gloves on occurrence of Acute disease.

Alternative Hypothesis $\left(H_{P}\right)$ :

There is a significant difference between mean of gloves users and respondents who do not use gloves on occurrence of Acute disease.

\section{Hypothesis for the t-test between wearing long} sleeves shirts and trousers on Acute diseases

Null Hypothesis $\left(H_{\theta}\right)$ :

There is no significant difference between mean of respondents who wear long sleeve shirts and trousers and respondents who do not wear long sleeve shirts and trousers on occurrence of Acute disease.

\section{Alternative Hypothesis $\left(H_{1}\right)$ :}

There is a significant difference between mean of respondents who wear long sleeve shirts and trousers and respondents who do not wear long sleeve shirts and trousers on occurrence of Acute disease. 


\section{RESULTS AND DISCUSSION}

\section{Profile of Vegetable Cultivating Farmers}

Result of the study on socio-economic variables of vegetable cultivators in Badulla district found that average age of farmers was 49.2 years with average experience in farming of 24.1 years. All of the respondent farmers were male and $89 \%$ of farmers were married, $9 \%$ of farmers were single and rests were divorced. The annual average income from vegetable cultivation was Rs. 182, 700.00 per acre (Table 01).

\section{Education Level of the Vegetable Farmers}

$3 \%$ of vegetable cultivating farmers had an education up to primary level and 33\% had secondary education and $61 \%$ tertiary education. The rest had higher education in Badulla district. This is more or less similar to the results of a previous study by Padmajani et al., (2014) in Badulla district where about $12 \%$ of farmers had primary education, $23 \%$ of farmers had secondary education and $63.5 \%$ of farmers had tertiary education and $1.5 \%$ of farmers had higher education. Figure 02 shows the percentages of education level of farmers at three different DS divisions of Badulla district.

\section{Type of Vegetable Cultivated in Badulla District}

Almost all the farmers cultivated up country vegetables in Badulla district. $86 \%$ of farmers cultivated cabbage (Brassica oleracea), from that $36.04 \%$ was in Uva-Paranagama, $33.72 \%$ was in Welimada and $30.23 \%$ was in Bandarawela. $83 \%$ of farmers cultivated potato (Solanum tuberosum), while only $30 \%$ of farmers cultivated leeks (Allium ampeloprasum) and among that 50\% was in Uva-Paranagama, $23.33 \%$ was in Welimada and $26.67 \%$ was in Bandarawela. $84 \%$ of farmers were cultivating tomato (Lycopersicon esculentum) and the same percentage was cultivating carrot (Daucus carota). $79 \%$ of farmers cultivated chilli (Capsicum annuum) and brinjal (Solanum melongena) among that $34.18 \%$ was in Bandarawela. 39\% of farmers cultivated radish (Raphanus sativus). From that $36.11 \%$ was in Uva- Paranagama. $68 \%$ of farmers cultivated beetroot (Beta vulgaris) and Knolkhol (Brassica oleracea) (Table 02).

Table 01: Socioeconomic characters of Vegetable Farmers

\begin{tabular}{lcc}
\hline \multicolumn{1}{c}{ Variables } & Mean & Std. Deviation \\
\hline Age (Years) & 49.2 & 9.01 \\
Vegetable cultivating Experience (Years) & 24.1 & 9.6 \\
Income from vegetable cultivation (Rs/ac/year) & 182700.00 & 43043.43 \\
\hline
\end{tabular}

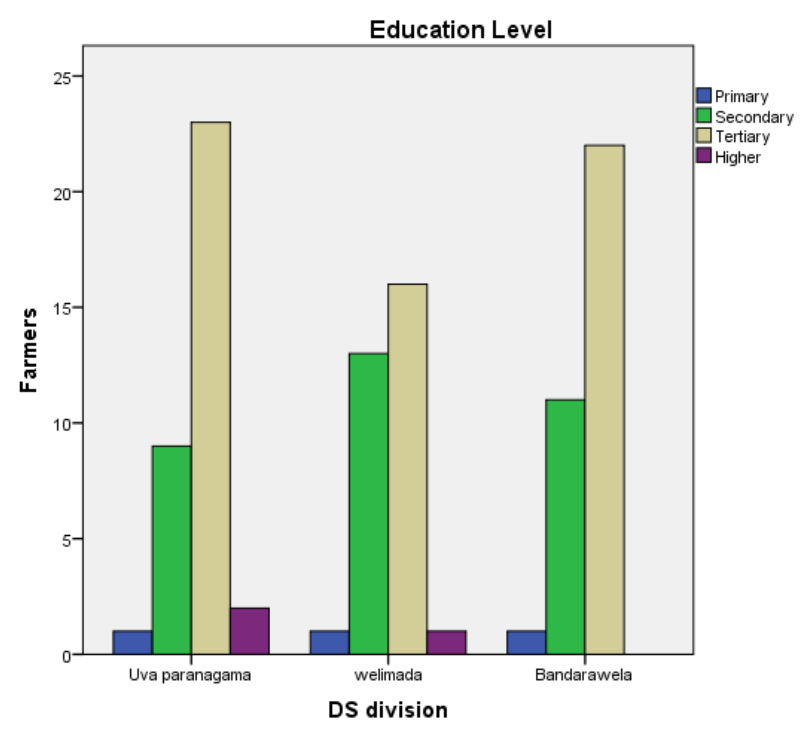

Figure 02: Education Level of Vegetable Cultivating Farmers 


\section{Table 02: Type of Vegetable Cultivated in Badulla District}

\begin{tabular}{lccc}
\hline \multirow{2}{*}{ Vegetable / Local Name (Scientific name) } & \multicolumn{3}{c}{ Percentage of Farmers Cultivating Vegetables } \\
\cline { 2 - 4 } & Uva-Paranagama & Welimada & Bandarawela \\
\hline Cabbage (Brassica oleracea) & 36.04 & 33.72 & 30.23 \\
Bean (Phaseolus vulgaris) & 35.29 & 31.76 & 32.94 \\
Potato (Solanum tuberosum) & 33.73 & 34.94 & 31.33 \\
Leeks (Allium ampeloprasum) & 50 & 23.33 & 26.67 \\
Tomato (Lycopersicon esculentum) & 34.52 & 27.38 & 38.09 \\
Carrot (Daucus carota) & 33.73 & 34.94 & 31.32 \\
Chilli (Capsicum annuum) & 32.91 & 32.91 & 34.18 \\
Brinjal (Solanum melongena) & 37.97 & 32.91 & 29.11 \\
Radish (Raphanus sativus) & 38.46 & 28.20 & 33.34 \\
Beetroot (Beta vulgaris) & 32.35 & 32.35 & 35.29 \\
Knolkhol (Brassica oleracea) & 43 & 43 & 14 \\
\hline
\end{tabular}

Table 03: Irrigation Method

\begin{tabular}{ccccc}
\hline DS Division & Gravity & Well & River & Sprinkler \\
\hline Uva-Paranagama & $80 \%$ & $5.71 \%$ & $74.28 \%$ & $8.57 \%$ \\
Welimada & $83.87 \%$ & $6.45 \%$ & $70.96 \%$ & $9.67 \%$ \\
Bandarawela & $91.17 \%$ & $5.88 \%$ & $55.88 \%$ & $5.88 \%$ \\
\hline
\end{tabular}

\section{Irrigation Method}

About $80 \%$ of farmers in Uva-Paranagama DS division and $83.7 \%$ and $91.7 \%$ of farmers in Welimada and Bandarawela were respectively using Gravity irrigation method. Whereas $5.71 \%$ of farmers in Uva-Paranagama were using well irrigation. About $74.28 \%$ of farmers in Uva-Paranagama DS division were depended on River irrigation (Table 03).

Insect Pest, Disease and Weeds Control in Badulla District

\section{Insect Pest Control in Badulla District :}

Almost all the farmers used chemical with cultural methods to control insect pest. Their average experience of insecticide application was 25.2 years. Average Frequency of insecticide application was 5.8 times per season.

\section{Time of Insecticide Application :}

About $13 \%$ of farmers in Uva-Paranagama DS division and $11 \%$ and $12 \%$ of farmers in Welimada and Bandarawela were spraying insecticide in the morning. About $6 \%$ of farmers in Uva-Paranagama and $2 \%$ and $3 \%$ of farmers in Welimada and Bandarawela were applying insecticide in the evening. About 16\% of farmers in Uva-Paranagama DS division and $18 \%$ and $19 \%$ of farmers in Welimada and Bandarawela respectively applied insecticides in both morning and evening.

Insecticides used in Vegetable Cultivation in Badulla District:

One of the most commonly used type of pesticides by vegetable farmers in Badulla district was insecticides. Among those insecticides, certain types of insecticides were most prominent among the vegetable farmers in Badulla district. About $91 \%$ of farmers used Marshal 20 SC (Carbosulfan) which is an Acetyl cholinesterase inhibitor, and among them $80.6 \%$ of farmers used above the recommended dosage. About $88 \%$ of farmers used Admire (Imidacloprid) which acts as a Nicotinic Acetylcholinereceptoragonists, and among them $60.2 \%$ of farmers applied Admire (Imidacloprid) above recommended dosage. 
About 94\% of farmers used Zoro (Abamactin) which is an extremely hazardous insecticide and among them $68.09 \%$ applied Zoro (Abamactin) above the recommended dosage. Zoro (Abamactin) is a Chloride channel activator and acts against nerve and muscle (Sparks and Nauen, 2015). 85\% of farmers used Calcrone (Profenofos) which is also an extremely hazardous insecticide, among them $25.89 \%$ of farmers used at recommended dosage, $67.06 \%$ of farmers used above the recommended dosage (Table 04).

\section{Disease control in Badulla District}

Almost all the farmers used chemicals with cultural methods to control diseases. Their average experience of Fungicide application was 25.22 years. Average Frequency of Fungicide application was 8.71 times per season. Almost all the fungicides were used above the recommended dosage by more than $50 \%$ of farmers.

\section{Time of Fungicide Application:}

About $13 \%$ of farmers in Uva-Paranagama DS division and $11 \%$ and $12 \%$ of farmers in Welimada and Bandarawela applied fungicide in the morning. $6 \%$ of farmers in Uva-Paranagama and $2 \%$ and $3 \%$ of farmers in Welimada and Bandarawela applied fungicide in the evening (Table 05).
Fungicides Used in Vegetable Cultivation in Badulla District:

Table 06 describes the different types of fungicides and the levels used in controlling diseases in vegetable farming in Badulla. Among those fungicides certain types of fungicides were most prominent among the vegetable farmers. About $93 \%$ of farmers used Mancozeb (Mancozeb 80\% w/w) and among them 74.20\% of farmers used above the recommended dosage. About $89 \%$ of farmers used Antracol (Proineb $70 \% \mathrm{w} / \mathrm{w})$. In a study by Liyanage et al., (2004) found fungicides were highly used in Potato cultivation where Propineb and Mancozebare were the most common fungicides used by potato cultivators. Majority $(93 \%)$ of farmers used Tizca (Fluazinam) to control fungal diseases and among that $78.49 \%$ of farmers used above the recommended dosage. $75.87 \%$ of farmers use Folicur (Tebuconazole) which is an extremely hazardous fungicide above the recommended dosage.

Although few farmers use pesticides in recommended dosage others used pesticides below the recommended dosage due to economic problems. They couldn't afford to buy pesticides. Usages of fungicides were high in crops such as potato, tomato compared to insecticides and weedicides, whilst the frequency of usage was high in fungicides.

Table 04: Insecticide Usage in Vegetable Cultivation

\begin{tabular}{llcccc}
\hline \multicolumn{1}{c}{ Trade Name } & Chemical Name & $\begin{array}{l}\text { Chemical sub group/ } \\
\text { Exemplifying active }\end{array}$ & Recommended & Above & Below \\
\hline Admire & $\begin{array}{l}\text { Imidacloprid } \\
\text { (Moderate hazard) }\end{array}$ & 4A Neonicotinoids & $23.86 \%$ & $60.23 \%$ & $15.91 \%$ \\
Marshal 20 SC & $\begin{array}{l}\text { Carbosulfan } \\
\text { (Extreme hazard) }\end{array}$ & 1A Carbamates & $19.35 \%$ & $80.65 \%$ & $0 \%$ \\
Zoro & $\begin{array}{l}\text { Abamactin } \\
\text { (Extreme hazard) }\end{array}$ & Avermectins, ilbemycins & $27.66 \%$ & $68.09 \%$ & $4.26 \%$ \\
Hanaro & $\begin{array}{l}\text { Bistrifluron } \\
\text { (Moderate hazard) }\end{array}$ & Benzoylureas & $22.41 \%$ & $70.69 \%$ & $6.99 \%$ \\
Calcrone & $\begin{array}{l}\text { Profenofos } \\
\text { (Extreme hazard) }\end{array}$ & 1B Organophosphates & $25.89 \%$ & $67.06 \%$ & $7.06 \%$ \\
Trebon & $\begin{array}{l}\text { Etofenprox } \\
\text { (Extreme hazard) }\end{array}$ & 3A Pyrethroids Pyrethrins & $28.07 \%$ & $61.40 \%$ & $10.53 \%$ \\
Avant & $\begin{array}{l}\text { Indoxacarb } \\
\text { (High hazard) }\end{array}$ & 22A Indoxacarb & $36.67 \%$ & $56.67 \%$ & $6.67 \%$ \\
Rimon & $\begin{array}{l}\text { Novaluron } \\
\text { (Extreme hazard) }\end{array}$ & Benzoylureas & $40.48 \%$ & $50 \%$ & $9.52 \%$ \\
\hline
\end{tabular}


Table 05: Time of Fungicide Application

\begin{tabular}{lccc}
\hline \multirow{2}{*}{ DS Division } & \multicolumn{3}{c}{ Time of Fungicide Application } \\
\cline { 2 - 4 } & Morning & Evening & Both \\
\hline Uva-Paranagama & $13 \%$ & $6 \%$ & $16 \%$ \\
Welimada & $12 \%$ & $2 \%$ & $18 \%$ \\
Bandarawela & $12 \%$ & $3 \%$ & $19 \%$ \\
\hline
\end{tabular}

Table 06: Fungicides Used in Vegetable Cultivation

\begin{tabular}{|c|c|c|c|c|c|}
\hline Trade Name & Chemical Name & $\begin{array}{l}\text { Chemical sub group/ } \\
\text { Exemplifying active }\end{array}$ & Recommended & Above & Below \\
\hline Daconil & $\begin{array}{l}\text { Chlorothalonil } \\
\text { (Moderate hazard) }\end{array}$ & Chloronitriles & $28.17 \%$ & $71.83 \%$ & - \\
\hline Mancozeb & $\begin{array}{l}\text { Mancozeb } 80 \%(w . w) \\
\text { (Low/slight hazard) } \\
\text { Metalaxyl }\end{array}$ & Dithiocarbamate & $23.55 \%$ & $74.20 \%$ & $2.15 \%$ \\
\hline Ridol & $\begin{array}{c}8 \%+\text { Mancozeb } 64 \% \\
\text { (Moderate hazard) }\end{array}$ & Acylalanines & $31.58 \%$ & $68.42 \%$ & - \\
\hline Folicur & $\begin{array}{c}\text { Tebuconazole } \\
\text { (Extreme hazard) }\end{array}$ & Triazoles & $23 \%$ & $75.87 \%$ & $1.15 \%$ \\
\hline Orius & $\begin{array}{c}\text { Tebucanazole } \\
\text { (Extreme hazard) }\end{array}$ & Triazoles & $42.86 \%$ & $52.63 \%$ & $5.27 \%$ \\
\hline Antracol & $\begin{array}{l}\text { Propineb70\% (w.w) } \\
\text { (Moderate hazard) }\end{array}$ & Dithiocarbamates & $32.59 \%$ & $66.3 \%$ & $1.12 \%$ \\
\hline Cabriotop & $\begin{array}{c}\text { Pyraclostrobin 5\%+ } \\
\text { Metiram 55\% WG } \\
\text { (Extreme hazard) }\end{array}$ & Methoxycarbamates & $31.81 \%$ & $68.18 \%$ & - \\
\hline Tizca & $\begin{array}{c}\text { Fluazinam } \\
\text { (Moderate hazard) }\end{array}$ & 2,6-Dinitroanilines & $18.28 \%$ & $78.49 \%$ & $3.23 \%$ \\
\hline
\end{tabular}

\section{Weed Control in Badulla District}

Almost all the farmers used chemicals with physical methods to control weeds. Their average experience of weedicide application was 24.32 years. Average Frequency of weedicide application was 1 time per season. Especially they used a weedicide namely Sencor in carrot cultivation to control the weeds. Reason for the low level of herbicide use in the cultivation of vegetable crops was that, there were low densities of weeds due to the continuous cultivation of vegetables. Another reason for low usage of weedicides in up country vegetable cultivation was the practice of manual weeding after crop establishment in the field. Recent researches elaborate that the risk of brain cancer is 2-fold high in those children whose mother exposed to agricultural pesticides especially herbicides during their job (Youn et al.,2009). And widespread use of herbicide increases the risk of meningioma (Claudine et al.,2008).

\section{Time of Weedicide Application:}

About $36 \%$ of farmers applied weedicide in the morning. $11 \%$ of farmers applied weedicide in the evening and the rest of farmers applied weedicide in both morning and evening.

\section{Weedicides Used in Vegetable Cultivation in Badulla District:}

All most all the farmers applied Sencor (Metribuzin 70\% w/w) and $43 \%$ of farmers used Sencor (Metribuzin 70\% w/w) above the recommended dosage. 
Awareness and Precaution of Pesticides Usage

\section{Awareness about Pesticides}

About $91 \%$ of the respondents had the idea that pesticides affect human health and $85 \%$ of respondents had the idea that pesticides affect the environment, about $83 \%$ of respondents thought that Pesticides were indispensable for high yield.

\section{Precaution of Pesticides Usage}

\section{Protective Covering:}

None of the farmers adopted full coverage of their body in pesticide application. But all farmers used at least one precautionary measure in pesticide application. About $51 \%$ of farmers used gloves during pesticide application and $81 \%$ of farmers used caps (Table 07). About $31 \%$ of farmers use mask and $5 \%$ of farmers use boots. About $46 \%$ of farmers wear long sleeve shirts and trousers during spraying. In a study in up country, about $36 \%$ of farmers used gloves, $67 \%$ of farmers used hats and $63 \%$ of farmers used masks and $6 \%$ of farmers used boots (Padmajaniet al .,2014) which supported present study.

\section{Other Common Precautionary Measures:}

All of the farmers had bought pesticide bottles with labels. About $92 \%$ of the farmers read the label on the pesticide bottle before using it. 95\% of the farmers washed the cloths separately which they were wearing during pesticide application. All most all of the farmers avoid splashing, spilling, leakage in sprayer.

\section{Identification of Pictograms on the Label}

The different pictograms related to protective measures of pesticides were shown to farmers and they were asked to identify the pictograms. Results of this are tabled on Table 08. Almost all farmers identified the pictogram of wearing gloves followed by $99 \%$ identified wearing boots. Only very few (2\%) identified the pictogram for wearing a protective apron.

\section{Consideration of Wind Direction:}

About $14 \%$ of farmers applied pesticides towards the wind direction in order to prevent the wind effect directly on chemical applicator; about $65 \%$ of farmers applied pesticides across the wind and $6 \%$ of farmers didn't apply when there was wind to avoid the wastage of pesticides. About 5\% of farmers didn't bother about wind direction (Table 09). Only a 10\% applied in the correct direction (perpendicular to wind blowing). In a study by Padmajani et al (2014) it was found that in Badulla district, farmers were conscious about the direction of wind during pesticide application, but $23 \%$ of them did not bother about the wind direction. The majority of farmers apply pesticides during the morning hours, but some prefer to apply insecticide in the evening as they believe insects are active in the evening.

\section{Hand Washing After Spray:}

Another basic principle needed to be adopted in working with pesticides for the personal protection is maintaining good hygiene to avoid direct contamination of pesticides. All the farmers washed their hands after spraying pesticides. About $96 \%$ of farmers washed their hands with soap for skin decontamination. 4\% of farmers washed hands only with water.

Table 07: $\quad$ Usage of Protective Covering

\begin{tabular}{lc}
\hline \multicolumn{1}{c}{ Protective Covering } & Percentage of Farmers Using \\
\hline Gloves & $51 \%$ \\
Cap & $81 \%$ \\
Mask & $31 \%$ \\
Boots & $5 \%$ \\
Wearing long sleeves shirts and trousers & $46 \%$ \\
\hline
\end{tabular}




\section{Table 08: Identification of Pictograms}

\begin{tabular}{|c|c|c|c|}
\hline \multirow[t]{2}{*}{ Pictogram } & Illustration & Identified & $\begin{array}{l}\text { Couldn't } \\
\text { identify }\end{array}$ \\
\hline & Handle carefully - liquid product & $3 \%$ & $97 \%$ \\
\hline & Handle carefully - dry product (powder or granular) & $9 \%$ & $91 \%$ \\
\hline & Apply with a hydraulic backpack sprayer & $50 \%$ & $50 \%$ \\
\hline & Wear gloves & $100 \%$ & $0 \%$ \\
\hline & Wash after handling & $91 \%$ & $9 \%$ \\
\hline & Wear a protective (waterproof or chemical-resistant) apron & $2 \%$ & $98 \%$ \\
\hline & Use a face shield to protect your eyes & $6 \%$ & $94 \%$ \\
\hline & Wear boots & $99 \%$ & $1 \%$ \\
\hline & Wear a mask & $80 \%$ & $20 \%$ \\
\hline & Wear protective coveralls & $63 \%$ & $37 \%$ \\
\hline & Dangerous / harmful to livestock and poultry. & $75 \%$ & $25 \%$ \\
\hline & Hazardous to Aquatic Organisms & $74 \%$ & $26 \%$ \\
\hline & $\begin{array}{l}\text { Keep locked away so that children and animals cannot } \\
\text { reach it. }\end{array}$ & $86 \%$ & $14 \%$ \\
\hline
\end{tabular}


Table 09: Consideration of Wind Direction

\begin{tabular}{lc}
\hline \multicolumn{1}{c}{ Consideration of Wind Direction } & Percentage \\
\hline Along with wind & $14 \%$ \\
Across with wind & $65 \%$ \\
Don't apply when wind & $6 \%$ \\
Don't consider wind & $5 \%$ \\
Perpendicular to wind blowing & $10 \%$ \\
\hline
\end{tabular}

\section{Disposal of Empty Container:}

About $7 \%$ of farmers reused the pesticide bottle for different purposes. About $10 \%$ of farmers buried empty pesticide bottles and bags. 32\% of farmers discarded them. $30 \%$ of farmers stored the empty bottles and packets as heap in a corner of the field. And the rest stored the empty containers in another separate container. The disposal of pesticide containers to the open environment is more hazardous to human beings and the environment. Some pesticides have long residual action and improper disposal will lead to serious threats. This could also be worsened by putting down of unused / balanced pesticide mixture.

Results found that almost all the farmers washed the sprayer after application of pesticide. $42 \%$ of farmers disposed washed water to field, about $23 \%$ of farmers disposed near irrigation channels. $21 \%$ disposed the sprayer washed water near a river and the rest disposed near a well where all of such are risky practices to the environment.

\section{Storage of Pesticides}

About $66 \%$ of respondents stored the pesticides in a storage room in their home, $19 \%$ of farmers stored pesticides in an open shed just only for storage of pesticides (Table 10). The rest of the farmers mostly had placed the bottles in unsafe locations in the house without considering safety precautions. Murphy et al., (2002) reported that storage of pesticides in unsafe places at homes is common in many developing countries and leads to health hazards.

\section{Activities after Spraying Pesticides:}

About $72 \%$ of farmers had a bath after application of pesticide and worked in the field and $16 \%$ of farmers continued their work in field after spraying and then had a bath. $12 \%$ of the farmers had a bath and taken a rest (Figure 03).

\section{Health Effect of Pesticide Application on Vegetable farmers}

Acute Disease

Acute diseases usually occurs after just one exposure, and symptoms develop within minutes to hours. Pesticides that cause acute toxicity can do so even with minimal exposure, depending on the strength or concentration (parts per million) of the pesticide. About $75 \%$ of farmers were affected by any type of acute disease and the rest had not been affected by any type of acute disease. Among them, about $52 \%$ of farmers were affected by skin problems followed by eye problems by $46 \%$ of farmers (Table 11). Jors et al., (2006) reported that adverse effects of pesticides poisoning ranges from headaches, vomiting, skin irritation, respiratory problems to other neurological disorders. In a study by Atreya et al., (2012) with vegetable farmers in Nepal revealed that headache, chest pain, irritation in eye and skin and throat discomfort were the major acute symptoms experienced frequently due to pesticide exposure. They further suggested that frequency of application of pesticides, work load, and the area under vegetable cultivation may enhance the incidence of acute diseases. 
Table 10: $\quad$ Storage of Pesticides

\begin{tabular}{lc}
\hline \multicolumn{1}{c}{ Storage of Pesticides } & Percentage \\
\hline Store room in the house & $66 \%$ \\
Open shed just for pesticides & $19 \%$ \\
Kitchen & $1 \%$ \\
Anywhere in the house & $4 \%$ \\
store room in the field & $10 \%$ \\
\hline
\end{tabular}

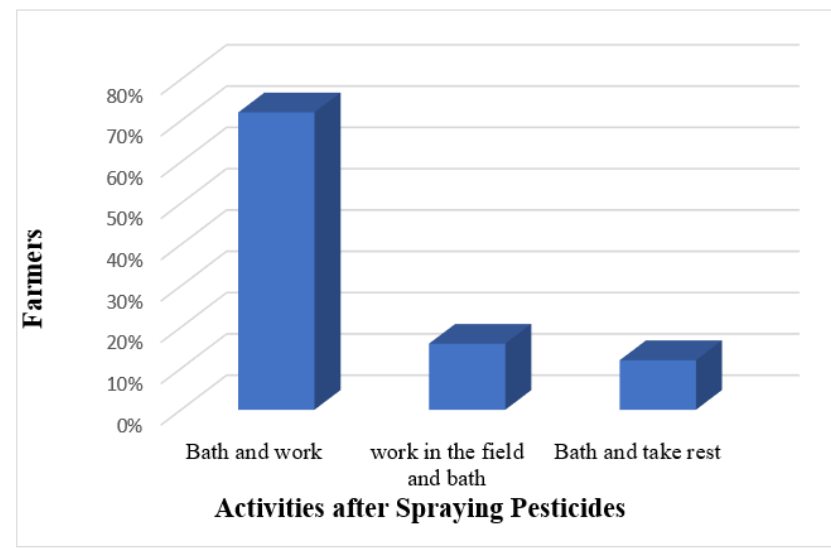

Figure 03: Activities after Spraying Pesticides

Table 11: Acute Disease

\begin{tabular}{lc}
\hline \multicolumn{1}{c}{ Acute Disease } & Percentage \\
\hline Skin problems & $52 \%$ \\
Nausea & $3 \%$ \\
Headache & $28 \%$ \\
Dizziness & $19 \%$ \\
Vomiting & $5 \%$ \\
Abdominal pain & $7 \%$ \\
Eye problems & $46 \%$ \\
\hline
\end{tabular}

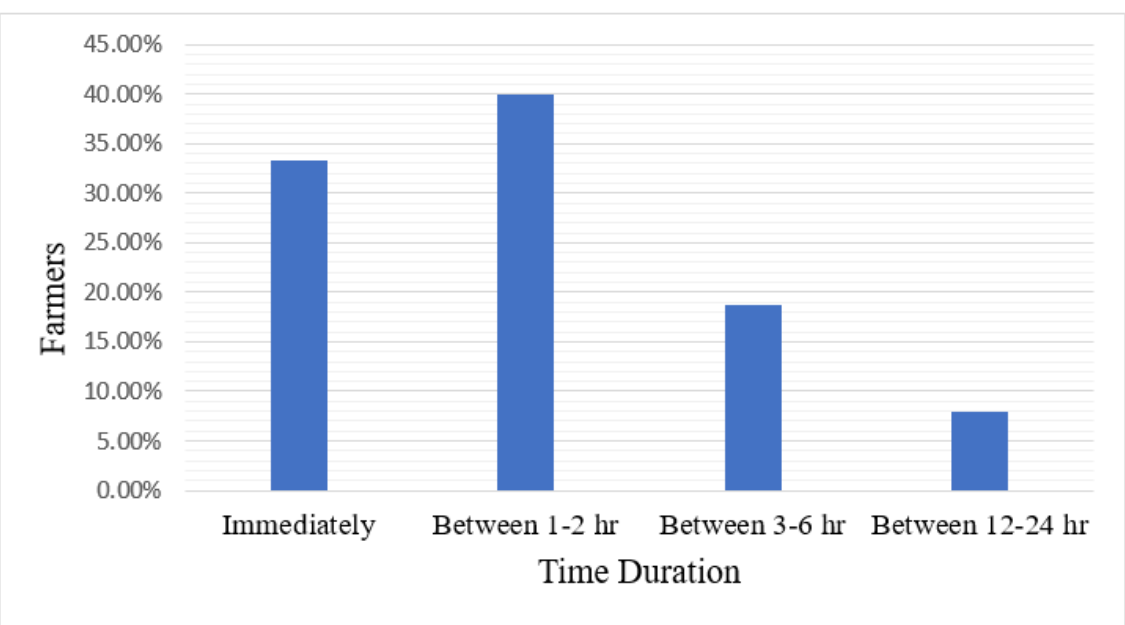

Figure 04: Time Duration between Observation of Acute Disease and Application of Pesticide 


\section{Time Duration between Observation of Acute Disease and Application of Pesticide}

Time taken for showing the symptoms of acute disease varied from person to person. $75 \%$ of farmers were affected by at least one acute disease and among that $33.34 \%$ of respondents showed the effects immediately after application of pesticides (Figure 04).

\section{Treatments for Acute Disease:}

$75 \%$ of farmers were affected by any one type of acute disease, and among them $2.67 \%$ of farmers did not get any treatment. $98.67 \%$ of farmers had got skin decontamination and airway protection treatment. They used soap and Dettol for skin decontamination and airway protection. About $44 \%$ of farmers had got gastrointestinal decontamination treatment; for that they had used lime juice and some Ayurvedic medicine. Only around $16 \%$ took treatment from hospitals for the acute diseases due to pesticides. .

\section{Health Cost for Acute Disease}

The average cost for the treatment to Acute disease was Rs.542.13 per treatment in Badulla district. In Sri Lanka, Wilson in a study (1998) has estimated that a farmer on an average incurs a cost of around US $\$ 49.33$ (Rs. 5465.00) per year whereas estimates by contingent valuation method gave a higher figure of Rs 11, 471.00.

\section{Hereditary Disease}

$3 \%$ of farmers suffer by wheezing and $2 \%$ of farmers had skin problems and $4 \%$ of farmers had diabetic other than acute disease. And the rest were not affected by hereditary diseases. Researchers found an association between wheezing and the use of pesticides by male farmers. (Senthilselvan et al., 1992).

\section{Other Disease}

Table 12 shows other diseases faced by the respondents. $1 \%$ of vegetable farmers family had cancer, $12 \%$ had blood pressure and 1\% suffered with kidney disease (Table 12).

\section{Death and Suicide due to Pesticides}

$1 \%$ of suicide cases was reported in the study area due to pesticide usage.

\section{Training and Awareness on Pesticides}

Formal source of extension service as the first priority of information source in selecting pesticides is limited only to $28 \%$ of the total farmers, while the rest mostly depends on pesticide dealers. Several studies in developing countries reveal that farmers usually source pesticide information from pesticide sellers and from other fellow farmers who have less knowledge on pesticide risks that leads to various pesticide related risks (Sodavy et al., 2000). Over $79 \%$ of farmers have an understanding of the environmental pollution and harmful effects on beneficial organisms in overdosing of chemicals, but $21 \%$ are not aware of groundwater contamination. Only $21 \%$ of the farmers have had some sort of training on pesticides. Out of the total trained participants, majority of the trainees $(63 \%)$ have attended training programmes conducted by private chemical companies as these programmes were implemented at field level and were easy to access by farmers.

\section{Table 12: $\quad$ Other Diseases}

\begin{tabular}{lc}
\hline \multicolumn{1}{c}{ Disease } & Percentage \\
\hline Cancer & $1 \%$ \\
Blood pressure & $12 \%$ \\
Kidney disease & $1 \%$ \\
Neurological disease & $4 \%$ \\
Allergenic sensitization & $17 \%$ \\
Not affected by other disease & $65 \%$ \\
\hline
\end{tabular}


Therefore, these farmers should be educated with eco-friendly methods such as Integrated pest management and biological control methods. Lekei et al., (2014) reported that Integrated Pest Management, safer application methods and use of less toxic agents or mechanical barriers to pests and usage of biological control agents are important ways to reduce reliance on, and, hence, human exposure to pesticides in agriculture. In a study by Krishnal et al., (2007) in Batticaloa district of Sri Lanka, a considerable number of vegetable farmers have knowledge on Integrated Pest Management and they practice the same to reduce the risk from pesticides. There is a need to introduce eco-friendly pest control methods to Badulla vegetable farmers.

\section{Reasons for Pesticide Usage}

There were several reasons for the use of pesticides in vegetable cultivation. $89 \%$ of farmers used pesticides because they felt it was an effective control method. About 93\% of farmers used pesticides due to quick control of insect pest. About 35\% of farmers used pesticides as they thought that it increased the production and $8 \%$ used, because the neighbors were using pesticides in vegetable cultivation.

\section{Hypothesis Testing}

Four hypothesizes were tested using t- test and the result of the analysis are shown below (Table 13).

\section{Results of T-test for training program on acute diseases:}

An independent-samples t-test was conducted to compare occurrence of Acute disease in person for those who had training on pesticide handling and for those who did not have training. Result shows that there was a significant difference $(p<0.05)$ in the occurrence of Acute diseases for persons who had the training and persons who did not have the training. Therefore, Null hypothesis was rejected.

\section{Hypothesis Testing for usage of masks on acute diseases}

Results of the independent-samples t-test on comparing the occurrence of Acute diseases in persons who used masks and did not use masks revealed a significant difference $(\mathrm{P}<0.05)$ in the occurrence of Acute diseases for persons who used masks and persons who did not use masks (Table 14). Null hypothesis was rejected.

\section{Hypothesis Testing for Usage of Gloves - T-test Result}

An independent-samples t-test was conducted to compare occurrence of acute disease in persons who used gloves and who did not use gloves. Result shows that there was no significant difference $(\mathrm{P}>0.05)$ in the occurrence of Acute diseases for persons who used gloves and persons who did not use gloves (Table 15). Therefore, null hypothesis was accepted.

Table 13: T-test for training program on acute diseases

\begin{tabular}{lccccc}
\hline \multicolumn{6}{c}{ T-test for Equality of Means } \\
\hline Training & $\begin{array}{c}\text { Mean } \\
\text { Difference }\end{array}$ & $\begin{array}{c}\text { Std. Error } \\
\text { Difference }\end{array}$ & $\mathrm{t}$ & df & Sig.(2-tailed) \\
\hline Equal variances assumed & .680 & .066 & 10.358 & 98 & .000 \\
Equal variances not assumed & .680 & .094 & 7.200 & 27.023 & .000 \\
\hline
\end{tabular}

Table 14: Hypothesis Testing for Usage of Mask - T-test Result

\begin{tabular}{lccccc}
\hline \multicolumn{6}{c}{ T-test for Equality of Means } \\
\hline \multirow{2}{*}{ Mask } & $\begin{array}{c}\text { Mean } \\
\text { Difference }\end{array}$ & $\begin{array}{c}\text { Std. Error } \\
\text { Difference }\end{array}$ & $\mathrm{t}$ & df & Sig.(2-tailed) \\
\hline Equal variances assumed & .333 & .103 & 3.252 & 98 & .002 \\
Equal variances not assumed & .333 & .112 & 2.965 & 35.735 & .005 \\
\hline
\end{tabular}


Table 15: Hypothesis Testing for Usage of Gloves - T-test Result

\begin{tabular}{lccccc}
\hline \multicolumn{6}{c}{ T-test for Equality of Means } \\
\hline \multirow{2}{*}{ Gloves } & $\begin{array}{c}\text { Mean } \\
\text { Difference }\end{array}$ & $\begin{array}{c}\text { Std. Error } \\
\text { Difference }\end{array}$ & $\mathrm{t}$ & df & Sig.(2-tailed) \\
\hline Equal variances assumed & .160 & .113 & 1.414 & 98 & .160 \\
Equal variances not assumed & .160 & .116 & 1.376 & 39.376 & .176 \\
\hline
\end{tabular}

Table 16: Hypothesis Testing for Usage of Wearing Long Sleeves Shirts and Trousers - T-test Result

\begin{tabular}{lccccc}
\hline \multicolumn{6}{c}{ T-test for Equality of Means } \\
\hline Wearing long sleeves shirts & $\begin{array}{c}\text { Mean } \\
\text { Difference }\end{array}$ & $\begin{array}{l}\text { Std. Error } \\
\text { Difference }\end{array}$ & $\mathrm{t}$ & df & Sig.(2-tailed) \\
\hline Equal variances assumed & .293 & .112 & 2.609 & 98 & .011 \\
Equal variances not assumed & .293 & .111 & 2.648 & 42.253 & .011 \\
\hline
\end{tabular}

Hypothesis Testing for Usage of Wearing Long Sleeves Shirts and Trousers

Results revealed that there was a significant difference $(\mathrm{P}<0.05)$ in the occurrence of Acute disease for persons who were wearing long sleeve shirts and trousers and persons who did not wear long sleeve shirts \& trousers and were without training (Table 16). Therefore, Null hypothesis was rejected.

\section{CONCLUSION}

Pesticides are used in vegetable cultivation to control insects, pests, diseases and weeds in Sri Lanka. But they are commonly toxic to human. The results of this study clearly indicate that farmers mostly depended on chemicals to control pests and most of them use extremely hazardous pesticides above the recommended levels. Even though they use precautionary measures, they were affected by pesticide related diseases. Most of the negative issues at the user's level were related to lack of awareness, negative attitudes and behaviors of farmers and weaknesses in the extension system. Therefore, a good extension education directing farmers towards other environmentally safer methods such as integrated pest management, organic farming and natural farming is needed. Farmers should also be educated on precautionary measures in handling pesticides and should impose to activate regulations on public health with regard to the use of hazardous pesticides.

\section{REFERENCES}

Atreya, K., Johnsen, F.H. and Sitaula, B.K., 2012. Health and environmental costs of pesticide use in vegetable farming in Nepal. Environment, Development and Sustainability, 14(4), pp.477-493.

Bolognesi, C., and Merlo, F. D. (2011). Pesticides: human health effects.

Central Bank of Sri Lanka (2018). Annual Report of Central Bank of Sri Lanka 2018.

Claudine M, Samanic A, Roos J, Patricia A (2008) Occupational exposure to pesticides and risk of adult brain tumors. Am J Epidemiol 167: 976-985. 
Jallow, M. F., Awadh, D. G., Albaho, M. S., Devi, V. Y., \& Thomas, B. M. (2017). Pesticide risk behaviors and factors influencing pesticide use among farmers in Kuwait. Science of the Total Environment, 574, 490-498.

Jors, E., Morant, R. C., Aguilar, G. C., Huici, O., Lander, F., Baelum, J., \& Konradsen, F. (2006). Occupational pesticide intoxications among farmers in Bolivia: a cross-sectional study. Environmental Health, 5(1), 10.

Kishi, M. (2005) The health impacts of pesticides: what do we know? In: Pretty, J. (ed.) The Pesticide Detox: Towards a More Sustainable Agriculture (pp. 23-38). London: Earthscan.

Krishnal, S., Raveendranath, S. and Hemachandra, K.S., 2007. Evaluation of the adoption of integrated management of vegetable. AGRIEAST, 6, pp.41-48.

Lekei, E.E., Ngowi, A.V. and London, L., 2014. Farmers' knowledge, practices and injuries associated with pesticide exposure in rural farming villages in Tanzania. BMC public health, 14(1), p.389.

Liyanage, J.A.; Watawala, R.C.; and Mallawatantri, A. (2004). "Risk based Evaluation of Fungicides Used in Potato Cultivation in the Up Country in Sri Lanka"Proceedings of the Second Bangi World Conference on EnvironmentalManagement, Bangi,Selangor, Malaysia.

Marasinghe, J. P. (2011). Human Health Risk Assessment of Organophosphate Pesticides in Sri Lanka. Griffith University.

Murphy, H.H., Hoan, N.P., Matteson, P. and Morales Abubakar, A.L.C., (2002). Farmers' selfsurveillance of pesticide poisoning: a 12-month pilot in northern Vietnam. International Journal of Occupational and Environmental Health, 8(3), pp.201-211.

Padmajani, M. T., Aheeyar, M. M. M., \& Bandara, M. A. C. S. (2014). Assessment of Pesticide Usage in Up-Country Vegetable Farming in Sri Lanka. Hector Kobbekaduwa Agrarian Research and Training Institute.

Senthilselvan, A., Mcduffie, H. H., \& Dosman, J. A. (1992). Association of asthma with use of pesticides. Am Rev Respir Dis, 146(4), 884-887.

Sodavy, P., Sitha, M., Nugent, M. and Murphy, H., (2000). Situation analysis: Farmers' awareness and perceptions of the effect of pesticides on their health. FAO Community IPM Programme.

Sparks, T. C. and Nauen, R. (2015). IRAC: Mode of action classification and insecticide resistance management. Pesticide biochemistry and physiology, 121, 122-128.

Van Der Hoek, W., Konradsen, F., Athukorala, K. and Wanigadewa, T., (1998). Pesticide poisoning: a major health problem in Sri Lanka. Social science \& medicine, 46(4-5), pp.495-504.

Wilson, C. (1998). Cost and policy implications of agricultural pollution with special reference to pesticides, Ph. D. Thesis, Department of Economics, University of Queensland, Australia

Wilson, C. and Tisdell, C. (2001) Why farmers continue to use pesticides despite environmental, health and Sustainability costs, Ecological Economics, v. 39, pp. 449-462.

Youn K, Shim S, Mlynarek P, Wijngaarden N (2009) Parental exposure to pesticides and childhood brain cancer: U.S. Atlantic coast childhood brain cancer study. Environ Health Perspect 117: 1002-1006. 